\title{
A Survey on Increasing Spelling Errors Due to Increase Use of Digital Technology Among Students
}

\author{
Ashwini.K1' M.P.Brundha ${ }^{2 *}$ and V.B.Preejitha ${ }^{3}$ \\ ${ }^{1}$ Saveetha Dental College and Hospitals, Saveetha Institute of Medical and \\ Technical Sciences, Saveetha University, Chennai-77,Tamil Nadu,India. \\ ${ }^{2}$ Associate Professor, Department of Pathology, Saveetha Dental College and Hospitals, Saveetha \\ Institute of Medical and Technical Sciences,Saveetha University, Chennai-77, TamilNadu, India \\ ${ }^{3}$ Tutor, Department of Pathology, Saveetha Dental College and Hospitals, Saveetha Institute of \\ Medical and Technical Sciences,Saveetha University, Chennai-77,Tamil Nadu,India.
}

\section{ABSTRACT}

In this digital era, technology has been accused of causing declining language standards. Interaction with digital technologies for work, play, and communication altered the intellectual pattern for development. Written communication through messaging, chat, and other forms of electronic communication developed a taxonomy of new knowledge. The problem in the digital age is that good language and strong spelling have become way more optional. Spell checking tools play a major role in hindering any room for creativity, style, and improvement of cognitive skills. The study aimed to check the concerns of spelling errors among the students in the digital era. A questionnaire was created, and a survey was taken among 100 students consistently who were using gadgets for their educational purposes. The questionnaire consists of 5 valid questions. The data was compiled and analyzed statistically. Descriptive and Chi square analysis was done.the results showed that the students are very much caring about their spellings when they type and giving more importance to avoiding spelling errors. Also we found that second year dental students and postgraduates are more concerned with spelling errors than the other students in the study population.The increasing use of technology has had an impact on increasing spelling errors. There is a considerable impact on spelling errors due to digital technology.

KEY WORDS: DIGITAL TECHNOLOGY, SPELLING ERRORS, SPELL CHECKERS, STUDENTS.

\section{INTRODUCTION}

In this digital era, technology has been accused of causing declining language standards (Andersson, 2015). Interaction with digital technologies for work, play, and communication altered the intellectual pattern for

\section{ARTICLE INFORMATION}

*Corresponding Author: brundha.sdc@saveetha.com Received 13th June 2020 Accepted after revision 4th August 2020 Print ISSN: 0974-6455 Online ISSN: 2321-4007 CODEN: BBRCBA

Thomson Reuters ISI Web of Science Clarivate Analytics USA and Crossref Indexed Journal

\section{Clarivate}

NAAS Journal Score 2020 (4.31) SJIF: 2020 (7.728)

A Society of Science and Nature Publication,

Bhopal India 2020. All rights reserved.

Online Contents Available at: http//www.bbrc.in/

Doi: http://dx.doi.org/10.21786/bbrc/13.7/41 development (Adams, 2004). Written communication through messaging, chat, and other forms of electronic communication developed a taxonomy of new knowledge (Varnhagen et al., 2010). Digital technology is an extensive source of information and entertainment. It is everybody's arena. The problem in the digital age is that good language and strong spelling have become way more optional (The Importance of Spelling and Handwriting in a Digital Age - Edublox Online Tutor | Development, Reading, Writing, and Math Solutions, 2017). This revolution has profoundly affected daily living (Schindler et al., 2017). Computer-mediated communication (CMC) a term used for communication produced with help from electronic devices. It plays a major role in the impact of standard 
spelling. There are both positive and negative aspects. Computer-based technology has infiltrated many aspects of life and industry.

Spelling is the learner's ability to write or spell out a word correctly (Othman, 2018). Accurate spellings help to enhance the quality of the writing texts. Spelling errors are when a learner consistently makes the same misspellings repeatedly because they do not know what is correct (Kusuran, 2017). It usually occurs because the students cannot distinguish between letters and sound of the words when they write (Siti and Muhammad, Zainal Muttaqien S.S.,M.Hum, 2017). There are 2 types of errors that people make: Topographic and cognitive errors. The former includes errors such as letter insertions, letter omissions, letter substitutions, and transpositions, whereas the latter from phonetic similarities (Kusuran, 2017). Exposure to incorrect versions can lead to greater difficulty discriminating correctly from incorrect versions. This increases the subsequent likelihood of misidentifying or generating an incorrect version as correct (Brown, 1990).

The increase of digital technology led to an increase in newer advancements where the spell checker tools are becoming practical for maintaining or enhancing database quality (Gardner, 1992). It is a function that automatically highlights a spelling mistake or error and suggests possible spelling correction by flagging out the errors. Spell-checkers also help them to revise and edit their written work, thus fewer surface errors will occur. It is also evident that learners displayed more vocabulary when using spell-checkers (Rimbar, 2017). Spell checking tools play a major role in hindering any room for creativity, style, and improvement of cognitive skills. This study aimed at the concerns of spelling errors made by the students due to increased use of digital technology.

\section{MATERIAL AND METHODS}

Sample collection: A survey was conducted among 100 students of Saveetha Dental College and Hospital in the month of November 2019. Nearly 5 valid questions had been prepared and circulated among the students and answers were recorded.

Inclusion Criteria: Selection criteria include all the dental students of Saveetha dental college who are willing to participate in the study. First, second, third and final year Undergraduate dental students and Interns all were included in the study. This study also included the postgraduate students of Saveetha Dental College. The age limit included in this study was 18-23 years.

Exclusion Criteria: Students who were not willing to participate were excluded from this study. The age less than 18 years and more than 23 years were not included in this study.

Sampling method: In the present study, the sampling method used is a random sampling method.
Data Collection and Tabulation: The responses were entered into the excel sheets and then tabulation of the data finally and the question comparison was done. The representation of the data is through the bar graph.

Statistical Analysis: The statistical software used IBM SPSS V22.The statistical tests used were descriptive analysis and Chi Square analysis. Significant $p$ value was set at $<0.05$.

Figure 1: Pie Chart shows the year of study of the sample population, in which $40.74 \%$ were 2 nd year BDS(red), $15.74 \%$ were 1 st year BDS (blue), $24.07 \%$ were post graduates dental students(light green), $7.41 \%$ were 3 rd year BDS(green), 7.41\% were interns (yellow)and 4.63\% were 4 th year BDS students(orange).

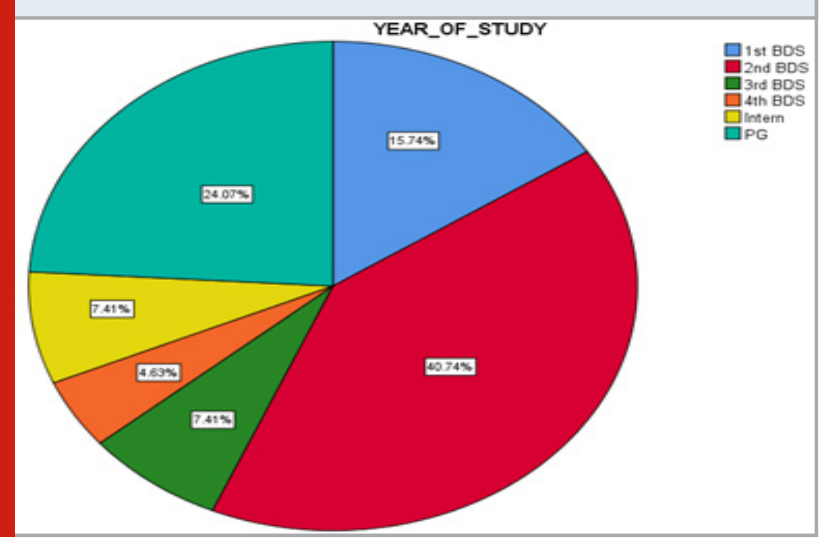

\section{RESULTS AND DISCUSSION}

The study included $40.74 \%$ were 2 nd year BDS, $15.74 \%$ were 1st year BDS, 24.07\% were post graduates dental students, 7.41\% were 3rd year BDS, 7.41\% were interns and $4.63 \%$ were 4 th year BDS students(Figure 1). Figure 2 represents the amount of care that students take for spelling of the words when they type. Around 53.7\% responded that they always take care, 25.93\% answered that they take care frequently, $17.59 \%$ for occasionally and $2.78 \%$ never concerned about their spelling when they type. As shown in Figure 3, 65.74\% answered that they commit spelling errors always, 15.74\% of the students agreed that they commit spelling errors occasionally, $14.81 \%$ of the students answered that they do spelling errors frequently and 3.7\% answered that they never do spelling errors.

When we analysed the association between the year of study and concern about the spelling errors we found that the majority of the second year BDS students, followed by Postgraduate students who always take care about the spelling when they type than the other students. However, the difference was not significant statistically. Pearson Chi square value of 22.25 and $P$ value of $0.101(>0.05)$ were obtained(figure 4$)$, the majority of the second year BDS students, followed by Postgraduate students make spelling errors occasionally when they type than the other students. However, the difference was not significant statistically. Pearson Chi 
square value of 17.07 and $P$ value of $0.314(>0.05)$ were obtained (figure 5) and majority of the second year BDS students, followed by Postgraduate students, have given more importance to spellings than the other year students and the difference is also significant statistically. Pearson Chi square value of 25.76 and $P$ value of $0.041(<0.05)$ were obtained.

Figure 2: Piechart represents the amount of care that students take for spelling of the words when they type. Around 53.7\% responded that they always take care (blue), 25.93\% answered that they take care frequently (red), $17.59 \%$ for occasionally and $2.78 \%$ never concerned about their spelling when they type.

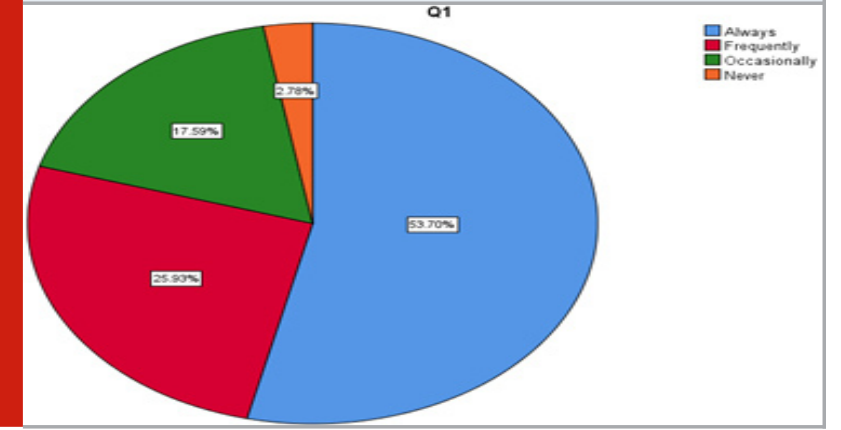

Figure 3: Pie Chart represents percentage response of the students who commit spelling errors. 65.74\% answered that they commit spelling errors always(blue), 15.74\% of the students agreed that they commit spelling errors occasionally (Dark green), $14.81 \%$ of the students answered that they do spelling errors frequently (red) and 3.7\% answered that they never do spelling errors(orange).

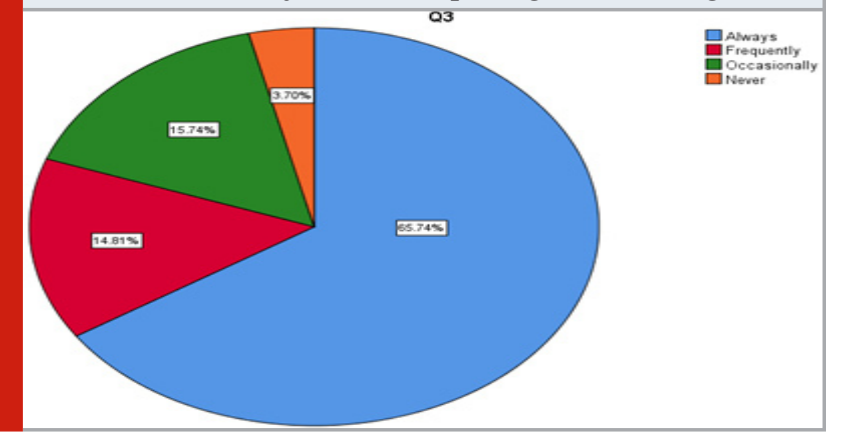

There is a lot of research and debate on the effectiveness of error correction and the contribution to improve and develop those error accuracy (Corpuz, 2011). The new emergence of word processors with spell checkers in this modern era has helped a lot in writing and spelling out wrong words (Lyster and Ranta, 1997). Spell checkers flag out the errors and provide an alternative or an apt word in replacement of that. The one thing about the spell checkers is that the learners must at least have a clue of how the word should be spelled. By knowing the spell checkers have a considerable influence on students' ability to generate repair of a spelling error, what language teachers in a Computer Assisted Language Learning (CALL) could do is to remain learners that spell checkers are not always correct.
They should also remind them to use spell checkers to check how the word is spelled and not just use them by clicking on the spelling suggestions and moving on. By doing this, the language learner can be more cautious while selecting suggested spelling and they will make sure to remember the corrections they have made. Limitations of the study is the biased distribution of the sample population. Future studies may be done with an unbiased sample distribution and with an analysis of spelling errors made by the students in text they type like research manuscripts, notes and assignments.

Figure 4: Bar graph shows the association between the year of study of sample population and their amount of care about spelling errors when they type (Chi square analysis). $\mathrm{X}$ axis represents year of study and $\mathrm{Y}$ axis represents the number of responses for the care about spelling errors. Majority of the second year BDS students, followed by Postgraduate students who always take care about the spelling when they type than the other students. However, the difference was not significant statistically. Pearson Chi square value of 22.25 and $P$ value of $0.101(>0.05)$ were obtained.

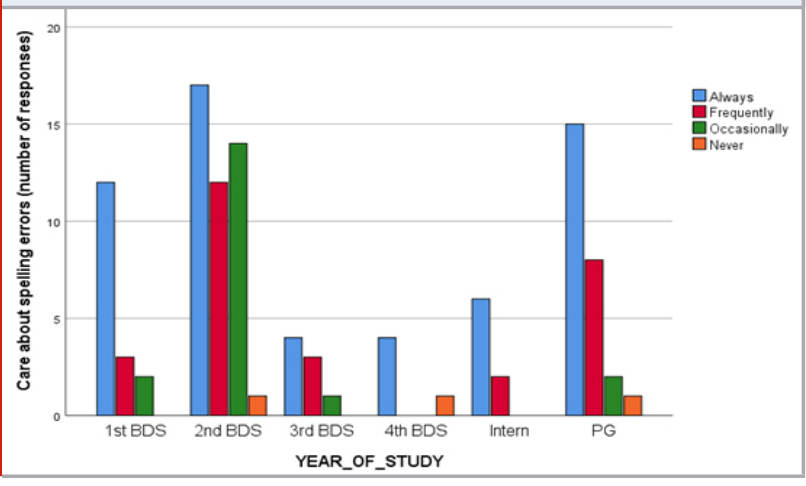

Figure 5: Bar graph shows the association between the year of study of sample population and frequency of spelling errors they make (Chi square analysis). $\mathrm{X}$ axis represents year of study and $Y$ axis represents the number of responses for frequency of spelling errors. Majority of the second year BDS students, followed by Postgraduate students make spelling errors occasionally when they type than the other students. However, the difference was not significant statistically. Pearson Chi square value of 17.07 and $P$ value of $0.314(>0.05)$ were obtained.

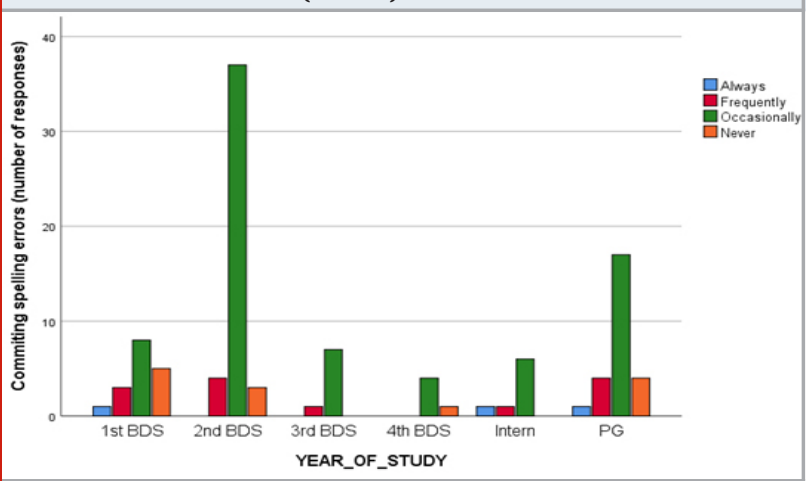


Figure 6: Bar graph shows the association between the year of study of sample population and the importance to learn the correct spelling given by the students(Chi square analysis). $\mathrm{X}$ axis represents year of study and $\mathrm{Y}$ axis represents the number of responses that students have given to spellings. Majority of the second year BDS students, followed by Postgraduate students, have given more importance to spellings than the other year students and the difference is also significant statistically. Pearson Chi square value of 25.76 and $P$ value of $0.041(<0.05)$ were obtained.

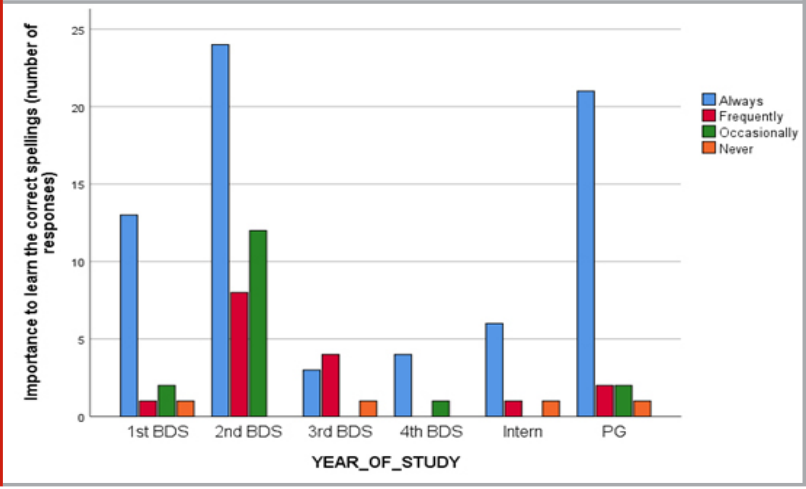

\section{CONCLUSION}

Within the limitations of the study, we conclude that the students are very much caring about their spellings when they type and giving more importance to avoiding spelling errors. Also we found that second year dental students and postgraduates are more concerned with spelling errors than the other students in the study population. The increasing use of technology has had an impact on increasing spelling errors. There is a considerable impact on spelling errors due to digital technology.

\section{ACKNOWLEDGEMENTS}

We thank Saveetha Dental College and the participants of this study for their support to conduct the survey.

Conflict of Interest: None to declare

\section{REFERENCE}

Adams, N. B. (2004) 'Digital Intelligence Fostered by Technology', The Journal of Technology Studies. doi: 10.21061/jots.v30i2.a.5.

Andersson, L. (2015) 'Does technology make us poor spellers? The effects of CMC on standard spelling'. Available at: https://www.semanticscholar.org/paper/38 04e2c2dfcfa9009442e0ce6d325155eda10c3f (Accessed: 30 June 2020).

Brown, A. S. (1990) 'A review of recent research on spelling’, Educational Psychology Review, pp. 365-397. doi: $10.1007 /$ bf01323630.

Corpuz, V. A. F. (2011) 'Error correction in second language writing: teachers' beliefs, practices, and students' preferences'. Available at: https://www.semanticscholar.org/paper/ b5b4c83e87090960809f658f357914177df85c81 (Accessed: 30 June 2020).

Gardner, S. A. (1992) 'Spelling Errors in Online Databases: What the Technical Communicator Should Know', Technical Communication. Society for Technical Communication, 39(1), pp. 50-53. doi: $10.2307 / 43095181$.

Kusuran, A. (2017) 'L 2 English spelling error analysis An investigation of English spelling errors made by Swedish senior high school students'. Available at: https://www.semanticscholar.org/ paper/fff698374431f780f9a6e33bf751423a30da9e25 (Accessed: 30 June 2020).

Lyster, R. and Ranta, L. (1997) 'CORRECTIVE FEEDBACK AND LEARNER UPTAKE', Studies in Second Language Acquisition, pp. 37-66. doi: 10.1017/ s0272263197001034.

Othman, A. K. A. (2018) 'An Investigation of the Most Common Spelling Errors in English Writing Committed by English-Major Male Students: At the University of Tabuk'. Available at: https://www.semanticscholar.org/ paper/dbda43001d09805e9d127f0734790b1 deb6e8686 (Accessed: 30 June 2020).

Rimbar, H. (2017) 'the Influence of Spell-checkers On Students' Ability To Generate Repairs Of Spelling Errors', Journal of Nusantara Studies (JONUS), 2(1), p. 1. doi: 10.24200/jonus.vol2iss1pp1-12.

Schindler, L. A. et al. (2017) 'Computer-based technology and student engagement: a critical review of the literature', International Journal of Educational Technology in Higher Education, 14(1), p. 25. doi: 10.1186/s41239-017-0063-0.

Siti, H. and Muhammad, Zainal Muttaqien S.S., M.Hum (2017) Spelling Error Analysis In Students' Writing At Tenth Grade In Man 1 Boyolali In The Academic Year Of 2016/2017. skripsi. IAIN Surakarta. Available at: http://eprints.iain-surakarta.ac.id/1312/ (Accessed: 30 June 2020).

The Importance of Spelling and Handwriting in a Digital Age - Edublox Online Tutor | Development, Reading, Writing, and Math Solutions (2017) Edublox Online Tutor | Development, Reading, Writing, and Math Solutions. Available at: https://www.edubloxtutor. com/importance-spelling-handwriting-digital-age/ (Accessed: 30 June 2020).

Varnhagen, C. K. et al. (2010) 'lol: new language and spelling in instant messaging', Reading and Writing, pp. 719-733. doi: 10.1007/s11145-009-9181-y. 